\title{
Innovative technology for the production of macaroni products made of emmer wheat flour
}

\author{
E. Khmeleva*, G. Osipova, T. Seregina and Yu. Rogacheva \\ Oryol State University named after I.S. Turgenev, 95, Komsomolskaya st., Oryol region, 302026, Russian Federation
}

\begin{abstract}
Macaroni products as a product of mass consumption can serve as an object for enriching the human body with useful components by using non-traditional raw materials. The authors propose an innovative technology for the production of macaroni products made of a mixture of wheat and emmer wheat flour with the addition of wheat bran as a source of dietary fibers, which makes it possible to give functionality to the products and at the same time improve their quality.
\end{abstract}

\section{Introduction}

Dishes made of macaroni products have long been favorite ones not only among the majority of Russian families, but also among citizens of many other countries of the world. The consumption of macaroni products in Russia is at a level comparable to European countries: if in the Russian Federation, on average, it is about $8 \mathrm{~kg}$ of macaroni products per person a year, then in Europe, except Italy, it equals $6.4 \mathrm{~kg}$ per person. European countries, particularly, Italy, Malta, Greece, Luxembourg, Croatia, Cyprus, Hungary, Germany and the Czech Republic, lead over Russia in per capita consumption of macaroni products $[1,2]$.

Such a love for macaroni products is quite reasonable, because they have a large number of advantages, such as storage duration, speed and simplicity of preparation, high nutrient availability, affordability.

The disadvantage of macaroni products from the point of view of biological value is the permission, in a number of countries, to use soft wheat flour (baking flour) for their production, which has a deficiency of the most important essential amino acids, primarily lysine, as well as minerals, vitamins and dietary fibers [3].

Taking into account the fact that macaroni products are the most widely used food products and are included in the food basket of the majority of consumers, this product can serve as an object for enriching the human body with useful components by using non-traditional raw materials [4].

The formulation of new recipes for macaroni products in order to change their chemical composition and give them functional properties has several vectors: enrichment with complete proteins, vitamin fortification and mineralization. To achieve this goal, a large number of non-traditional supplements for macaroni products production are used. Thus, protein isolates, products of animal origin, buckwheat flour, soy processing products, sesame seeds, flax seeds, chickpeas, etc. are used as enriching supplements to replete the protein deficiency [5-8].

Fruits, berries and vegetables powders, cakes and meals, medicinal plant raw materials, herbs, algae, various types of flour, etc. are widely used for the correction of vitamin and mineral compositions [9-14].

The enrichment of macaroni products with the components rich in dietary fibers can be specified separately. Previously, it was believed that carbohydrates that are not digested in the human body are useless, irritate the intestinal mucosa and in what form they enter the human body, in this form they excrete.

The scientific researches of domestic and foreign scientists highlight the physiological role of dietary fibers in the prevention of various diseases. Literature data on the effect of dietary fibers on the human body emphasize their effectiveness in the prevention of cardiovascular diseases, obesity, diabetes and other diseases.

Currently, the enrichment of food with dietary fibers is widely used in the food industry that gives an opportunity to increase the macronutrient status of the population's nutrition. Therefore, the enrichment of traditional products, namely macaroni products, with dietary fibers is an important and vital task.

Sources of non-traditional raw materials and supplements containing dietary fibers can be processed products made of vegetable raw materials, grain varieties and their mixtures, etc. [15-20].

Scientists of Moscow State University of Food Production have formulated recipes for macaroni products using non-traditional raw materials-mainly, buckwheat flour, which has a number of advantages in terms of nutrient composition compared to wheat flour, with added dietary fibers - inulin and fiber with a high degree of fiber length [20].

\footnotetext{
Corresponding author: hmelevaev@bk.ru
} 
Oryol State Technical University has developed new types of macaroni products enriched with Orafti @ GR inulin and wheat fiber.

N. N. Tripsina and co-authors in their scientific work propose to use rice and buckwheat flour as sources of dietary fibers which also contain complete proteins, a wide spectrum of B vitamins, nicotinic acid, macro-and microelements, and polyunsaturated fats [21].

A method of using whole meal multigrain flour processed from oatmeal and barley for the production of macaroni products is well-known. These supplements help to increase the content of nutrients useful for the human organism: dietary fibers, micro-and macronutrients, as well as to increase the biological value of the product [22].

Scientists of South Ural State University studied the possibility of using whole meal multigrain flour in the recipe of group "B" macaroni products of the highest grade for the first course. It was found that the substitution of $30 \%$ of wheat flour in the composition of macaroni products for the barley-rye-oat one contributes to an increase in the content of dietary fibers in the finished product (by $44.6 \%$ ), lipids, microelements: copper, zinc, iron, manganese, macronutrients: magnesium and phosphorus against the background of the formation of good quality and acceptable cooking properties [23].

One of the promising ways to enrich macaroni products with dietary fibers and give them functional properties is the use of non-traditional plant raw materials for this type of product - emmer wheat flour, in particular, which has a number of advantages in terms of nutrient composition compared to wheat flour, as well as the introducing dietary fibers in the recipe.

Emmer wheat (Triticumdicoccum, amelcorn) belongs to the ancient chaffy wheat, is unpretentious to the cultivation conditions, resistant to agricultural diseases, fast-growing, has a rich chemical composition. Emmer wheat exceeds soft wheat in the content of dietary fibers (by 2.65 times), as well as protein, reducing sugars, polyunsaturated fatty acids, some vitamins (pantothenic, folic acids and choline) and minerals (magnesium, phosphorus, zinc, manganese) [24].

Currently, the cultivation of spelt, the ancient crop, in Russia and abroad has increased.

The interest in spelt is not accidental: farmers, having realized the huge potential of this crop, which is expressed in adaptability and resistance to diseases and pests, unpretentiousness to the conditions of cultivation, adaptability to overcome adverse environmental factors, cultivate spelt using environmentally friendly technologies without the use of fertilizers and pesticides, which make it possible to obtain organic products that are in great demand nowadays.

Earlier, hull content of this crop was considered to be a negative factor, but today it is an advantage in comparison with standard hulless wheat, allowing producing demanded environmentally friendly raw materials of plant origin.

It is also known that spelt contains mucopolysaccharides that contribute to the strengthening of the immune system of the human body, and polyphenol compounds that have anti-mutagenic and anti-carcinogenic effects.

Spelt attracts more and more attention of healthy diet supporters and is also of interest to the food industry from the standpoint of expanding the raw material base and the range of products, including functional and nutritional food.

Figure 1 shows the advantages of spelt, which make it promising for producing of environmentally friendly, functional and enriched food.

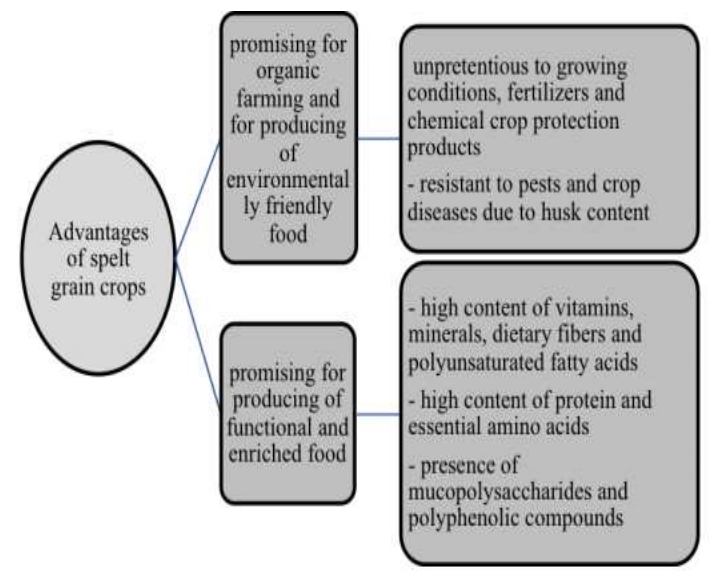

Figure 1. Advantages of spelt grain crops.

The purpose of the research was to develop a technology for the production of macaroni products as functional food using emmer wheat flour and wheat bran.

\section{Materials and methods of research}

The objects of research are emmer wheat flour produced from emmer wheat grain Triticumdicoccum (Schrank.) Schuebl., of Runo variety cultivated in Oryol region; wheat bakery flour of the highest grade; wheat bran; pasta; macaroni products.

Methods for studying the technological properties of flour: the content and properties of gluten - according to GOST 27839-2013, the water absorption capacity of gluten, the rheological properties of the dough-according to the method specified in [5], the cooking properties of macaroni products - according to GOST 31743-2017.

\section{Results of research}

To carry out the research, the main raw material used was wheat flour "Makfa" of the highest grade with the following quality indicators: the content of raw gluten$31.68 \%$; the content of dry gluten-10.39\%; GDM -65 un. pr.; the water absorption capacity of raw gluten$204.9 \%$.

The quality indicators of emmer wheat flour are as follows: the content of raw gluten - $22.64 \%$; the content of dry gluten - $7.87 \%$; GDM - 72 units, pr.; the water absorption capacity of raw gluten $-187,6 \%$.

To prove the technological suitability and the possibility of using emmer wheat flour in the production of macaroni products, it is necessary first of all to 
evaluate their properties, which are determined by the following indicators: the amount of gluten, the content of carotenoid pigments, the content of dark inclusions, the coarseness of grinding.

The presence of carotenoid pigments and dark inclusions play, to a greater extent, an aesthetic role, determine the organoleptic properties of macaroni products.

The current reference document on enriched macaroni products (emmer wheat flour is considered to be an enriching agent in this case) requires that "the color of products using supplementary raw materials changes depending on the type of this raw material", that is, products with the use of emmer wheat flour, by definition, will be darker in color.

Among all macaroni products properties mentioned above, the content of raw gluten and its properties, and in addition, the properties of starch as a structureforming component are essential.

It is a common fact that to obtain high-quality macaroni products, the content of raw gluten in wheat flour should be at least $28 \%$, that is, the analyzed emmer wheat flour can only be used in a mixture with wheat flour.

Another argument in favor of using a mixture of wheat and emmer wheat flour is a slightly different fractional composition of emmer wheat protein from soft wheat, which includes a much smaller amount of gluten proteins (gliadin and gluten) and, first of all, the gliadin fraction of gluten, which is responsible for its binding capacity.
Earlier studies have shown that it is impossible to use emmer wheat flour as the main raw material (due to the low content of raw gluten for macaroni products production) and it should be mixed with wheat flour.

Using previously derived formulas for calculating the maximum dosage of any supplements added instead of a part of wheat flour, taking into account the amount of raw gluten in wheat flour and the supplement, it was established that the ratio of wheat flour and emmer wheat flour when mixing pasta is 50:50 (variant 1) and $66.7: 33.3$ (variant 2), the dosage of wheat bran is $6 \%$ to the amount of flour.

To obtain dough for the production of macaroni products, wheat and emmer wheat flour and wheat bran were pre-mixed in the required ratio, the mixture was sifted.

Then the dough was kneaded. The amount of water per mixture was determined by calculation to a dough humidity which equals $28 \%-34 \%$, taking into account the humidity of wheat and emmer wheat flour mixture, as well as the humidity of wheat bran. The duration of dough kneading was 10-15 minutes.

Further, the prepared pasta was recovered in an extrusion barrel, cut to produce semi-finished macaroni product, then cutting, blasting, lay out, drying, stabilization and cooling procedures in accordance with the traditional scheme of the technological process were carried out.

Table 1 shows the effect of emmer wheat flour and wheat bran on the properties of raw gluten and flour starch, the rheological properties of pasta, and the cooking properties of macaroni products.

Table 1. Raw gluten and flour starch properties, rheological properties of pasta and cooking properties of macaroni products.

\begin{tabular}{|c|c|c|c|c|}
\hline \multirow[t]{3}{*}{ Indicator } & \multicolumn{4}{|c|}{ Sample } \\
\hline & \multirow{2}{*}{$\begin{array}{l}\text { Wheat } \\
\text { flour }\end{array}$} & \multirow{2}{*}{$\begin{array}{c}\text { Emmer } \\
\text { wheat } \\
\text { flour }\end{array}$} & \multicolumn{2}{|c|}{ Control sample: } \\
\hline & & & variant 1 & variant 2 \\
\hline $\begin{array}{l}\text { Amount of raw gluten, } \\
\mathrm{g} / 100 \mathrm{~g} \text { of flour (mixture) }\end{array}$ & $31.68 \pm 0.2$ & $22.64 \pm 0.2$ & $27.85 \pm 0.2$ & $28.20 \pm 0.2$ \\
\hline GDM, un.pr. & 65.00 & 72.00 & 50.00 & 47,50 \\
\hline $\begin{array}{l}\text { Water absorption capacity } \\
\text { of gluten, } \%\end{array}$ & $204.90 \pm 0.2$ & $187.60 \pm 0.2$ & $204.18 \pm 0.2$ & $215.55 \pm 0.2$ \\
\hline $\begin{array}{l}\text { Temperature of the } \\
\text { maximum viscosity of the } \\
\text { starch gel, }{ }^{\circ} \mathrm{C}\end{array}$ & 91.00 & 85.00 & 91.25 & 92.50 \\
\hline Maximum shear stress, $\mathrm{kPa}$ & 2.58 & 2.40 & 4.27 & 6.07 \\
\hline $\begin{array}{l}\text { Dry matter loss in the } \\
\text { cooking water, } \%\end{array}$ & $3.27 \pm 0.2$ & - & $3.29 \pm 0.2$ & $3.34 \pm 0.2$ \\
\hline
\end{tabular}

Adding emmer wheat flour and wheat bran into the pasta increases the elastic properties of raw gluten (per 15-17.5 un. pr. GDM), the main rheological characteristic of the pasta is the maximum shear stress (by $1.65-2.35$ times), increases the temperature of the maximum viscosity of the starch gel (by $0.25-1.5{ }^{\circ} \mathrm{C}$ ), which as a result contributes to the development of highquality macaroni products with high cooking properties (the amount of dry substances that have been lost in the cooking water does not exceed $6 \%$, as required by the reference document (GOST 31743-2017 Macaroni products. General technical specifications).

A slight increase of this indicator (by $0.02 \%-0.07$ $\%$ ) compared to the same indicator of the control sample is due to emmer wheat flour properties: water - and saltsoluble proteins prevail in emmer wheat protein and the content of gliadin and glutenin fractions is significantly lower than in wheat flour.

This leads to a decrease in the binding capacity of raw gluten, for which the gliadin fraction is responsible, while low-molecular-weight protein fractions first lost in the cooking water. 
Wheat bran compensates for the effect of emmer wheat flour, which has a firming effect on the properties of raw gluten, has a high water absorption capacity, which increases the viscosity of the pasta, and is involved in the structure-forming process of macaroni products.

The mixed supplement of emmer wheat flour and wheat bran to the macaroni products recipe changes their chemical composition, in particular the amount of dietary fibers.

Table 2. The content of dietary fibers in the macaroni products.

\begin{tabular}{|c|c|c|c|}
\hline \multirow[t]{2}{*}{ Indicator } & \multirow[t]{2}{*}{$\begin{array}{l}\text { Macaroni } \\
\text { products } \\
\text { (prototype) }\end{array}$} & \multicolumn{2}{|c|}{$\begin{array}{l}\text { Macaroni products with } \\
\text { emmer wheat flour and } \\
\text { wheat bran: }\end{array}$} \\
\hline & & variant 1 & variant 2 \\
\hline $\begin{array}{l}\text { Fiber, } \\
\mathrm{mg} / 100 \mathrm{~g}\end{array}$ & 1.95 & 3.23 & 5.34 \\
\hline
\end{tabular}

The initial content of dietary fibers in the composition of emmer wheat flour is $3.8 \mathrm{~g} / 100 \mathrm{~g}$; in the composition of wheat bran is $42.6 \mathrm{~g} / 100 \mathrm{~g}$. If their content is $1.95 \mathrm{~g}$ per $100 \mathrm{~g}$ of the product in the control sample, then it equals $3.23 \mathrm{~g} / 100 \mathrm{~g}$ (variant 1) and 5.34 $\mathrm{g} / 100 \mathrm{~g}$ (variant 2) in the proposed compositions.

The physiological need for dietary fibers for an adult is $20 \mathrm{~g} /$ day, i.e. the daily need is met by $16.15 \%$ in the first variant; and in the second one - by $26.7 \%$.

This gives the reason to include macaroni products made of the proposed dough compositions to functional products, since the content of the functional ingredient, dietary fibers in particular, is more than $15 \%$ of the daily requirement.

\section{Conclusion and recommendations}

A technology for the production of macaroni products made of a mixture of wheat and emmer wheat flour with the supplement of wheat bran as a source of dietary fibers has been developed, which makes it possible to give functionality to the products and at the same time improve their quality.

The developed technology for the production of pasta made from spelt flour with the addition of bran received a patent of the Russian Federation 2741104.

\section{References}

1. D.R. Aptrakhimov, M.B. Rebezov, Modern business space: actual problems and prospects, 2(3) (2014).

2. A.M. Agapkin, I.A. Makhotina, YU.D. Belkin, International trade and trade policy, 2(18) (2019).

3. P.V. Medvedev, V.A. Fedotov, I.A. Bochkareva, Bread products, 8 (2016).
4. E.B. Tyurina, Bread products, 12 (2017).

5. G.A. Osipova Theoretical and experimental substantiation of the development of new types of macaroni products of increased nutritional value (dissertation for the degree of Doctor of Technical Sciences) (2012).

6. D.A. Kalitka, B. Amanzhol, A.M. Saidov, Mechanics and technologies, 1(63) (2019).

7. E.I. Verboloz, V.T. Antufyev, O.I. Nikolyuk, Bread Products, 11 (2016).

8. R.A. Fedorova, V.S. Volkov, V.U. Novikova, Izvestiya of Saint Petersburg State Agrarian University, 5 (2017).

9. S.E. Nikolaeva, V.V. Tarasova, A.P. Nechaev, Vestnik of Nizhnevartovsk State University, 2 (2019).

10. A.Sh. Sanaev, P.M. Tursunkhodzhaev, N.K. Aikhodzhaeva, O.T. Umarov, Chemistry and chemical technology, 2(68) (2020).

11. G.B. Shambyl, S.A. Altayuly, S.A. Kardenov, International Student Scientific Bulletin, 3 (2019).

12. O.F. Fazullina, S.O. Smirnov, Polzunovsky bulletin, 4 (2020).

13. Patent No. 2607350 Russian Federation, IPC A23L 7/109. Macaroni products for preventive purposes declared on 24.07.2015: published on 10.01.2017

14. T.B. Akhlan, G.E. Zhumalieva, B.J. Muldabekova, Bulletin of Almaty Technological University, 3 (2020).

15. E.V. Strigulina, Bread products, 2 (2019).

16. A.B. Samuelsen, A. Rieder, S. Grimmer, T.E. Michaelsen, S.H. Knutsen, Int. J. Mol. Sci., 12 (2011).

17. H. Zeng, D.L. Lazarova, M. Bordonaro, World J. Gastrointestinal Oncology, 6 (2014).

18. S.P. Merenkova, O.V. Zinina, M. Stuart, Sport. Medicine, 20 (2020).

19. I. Kosović, M. Benšić, Đ. Ačkar, Foods and Raw Materials, 6(2) (2018).

20. Yu.V. Nikolaeva, A.P. Nechaev, V. Tarasova, Confectionery and bakery production, 1-2 (185) (2020).

21. N. Trypsina, G.V. Blagodarova, A.E. Tumanova, Food industry, 3 (2021).

22. E.V. Zhukova, N.L. Naumova, Technology and commodity science of innovative food products, 6(59) (2019).

23. Ju, Betz, N.L. Naumova, O. Burmistrova, Bulgarian Journal of Agricultural Science, 26(6) (2020).

24. O.V. Chugunova, E.V. Kryukova, Scientific bulletin, 3 (2015). 